Revista Brasileira do Esporte Coletivo - v. 4. n. 2. 2020.

\title{
ARREMESSOS ESPECIAIS NO HANDEBOL, UMA ABORDAGEM PEDAGÓGICA. ROSQUETA NO HANDEBOL
}

\author{
${ }^{1}$ Ronaldo da Cunha Nascimento; ${ }^{2}$ Lúcio Carlos Dias Oliveira.
}

\begin{abstract}
RESUMO
Introdução: No handebol há vários tipos de arremessos que podem ser utilizados pelos alunos/atletas para realização de um gol. Dentre eles, destaca-se a rosqueta pelo efeito especial de plasticidade que a bola produz em termos de espaço, corporeidade, cognição e definição do lançamento. Objetivo: Discutir e refletir o sentido da práxis pedagógica do professor sobre a execução de um arremesso especial denominado rosqueta no handebol, este envolve aspectos da cognição, motores e autonomia do indivíduo. Método: A pesquisa partiu de observações e vivências anteriores e fundamenta-se na pesquisa bibliográfica de característica narrativa, que busca discutir acerca da ação gestual do arremesso rosqueta, que por sua vez envolve uma série de fatores vivenciados no processo de ensino aprendizagem e treinamento. Discussão: $\mathrm{Na}$ aprendizagem da rosqueta, o processo é longo, até que o indivíduo entenda a intenção, a necessidade e a razão da aplicabilidade desse arremesso, sendo capaz de decidir qual o melhor momento de executá-lo. Conclusão: Diante dessas proposições descritas, é possível afirmar que o aluno/atleta esteja sendo comprometido por seus processos cognitivos e motores que envolvem a condução da aula/treino, junto ao comportamento do professor, que eleva a liberdade e a criatividade desse indivíduo em realizar o que deve ser feito.
\end{abstract}

Palavras Chaves: Arremesso, cognição, gesto, handebol, rosqueta.

\section{SPECIAL THROWS IN HANDEBOL, A PEDAGIGICAL APPROACH.}

\section{ABSTRACT}

Introduction: In handball there are several types of pitches that can be used by students/ athletes to score a goal. Among them, the pitch shot due to the special plasticity effect that the ball produces in terms of space, corporeality, cognition and definition of the launch. Objective: To reflect the sense of the teacher's pedagogical praxis, and the appropriation of knowledge in the formation of handball sports categories. It also questions the aspects of psychomotricity that promote this type of pitch, in an action that can be learned; or not, with dynamics and creativity. Method: The research starts from the participant observation in the execution of the República dos Esportes project, which trains sports categories in all age groups. It is based on bibliographic research of a narrative characteristic, of authors who theoretically support the teacher's pedagogical practice. Discussion: This article seeks to discuss about this gestural action, which in turn involves a series of physical and psychological factors, experienced in the teaching-learning process. Conclusion: It is understood that the donut pitch is not an insurmountable system, tied in closed gestural codes, but the manifestation of the use of freedom, which the student / athlete needs to understand that he has in the use of such codes, derived from psychomotricity information, to establish the relationship between freedom and bodily awareness and from that relationship, starting to exercise corporeality using its creative and empathic autonomy; it was a priori, the target of this work.

Keywords: pitch, cognitive gestures, handball, pitch shot due.

${ }^{1}$ Prof. Especialista em Docência do Ensino Superior. Aux. Técnico de handebol do Centro FAG Cascavel - PR. Idealizador do projeto República dos Esportes Macapá.

${ }^{2}$ Doutorando em Educação - ULUSOFONA - PORTUGAL. Prof. Ms. Efetivo da Universidade Federal do Maranhão - UFMA.

Email: handnal973@gmail.com.

\section{INTRODUÇÃO}

O presente artigo propõe uma reflexão teórica do arremesso especial conhecido usualmente como rosqueta, com base em observações feitas nos jogos europeus, e da práxis cotidiana das atividades esportivas aplicadas no decorrer de aulas, treinos e 
cursos conduzidos no fazer profissional, ao longo de quase vinte anos. Tempo esse, aonde vem sendo desenvolvido quase que de forma exclusiva a execução do projeto República dos Esportes, que visa por meio do esporte, capacitar crianças de ambos os sexos, nas categorias de base, jovens e adultos, na prática esportiva de handebol.

$\mathrm{Na}$ construção dos argumentos apresentados buscou-se fazer um diálogo com autores que defendem o saber elaborado na aquisição do conhecimento em sua totalidade, Morin (2000) e de autores que militam na defesa do movimento corpóreo como um instrumento de desenvolvimento (OLIVER, 1995).

Os estágios da vida dos indivíduos são assinalados por permanentes aprendizagens, disso decorre que o processo de ensinar e aprender envolve fatores interdependentes; dentre eles as fases da aprendizagem que precisam ser observadas e garantidas pelos educadores; assim como: fatores emocionais, psíquicos e socioeconômicos. O que em nenhuma hipótese podem ser ignorados, a fim de que o processo formativo não seja comprometido. A aprendizagem, portanto, é um processo de apropriação de variadas informações e modos de ação física e mental, sistematizados e orientados no processo de ensinar e aprender (PIAGET, 1999).

Por isso a necessidade do conhecimento socialmente estruturado desde as categorias de base. Nessa defesa Dehaene (2018), apresenta que o conhecer é um processo que passa por etapas, que autor chama de "Pilares da aprendizagem", e que também necessita ser assegurado no pleno desenvolvimento das funções cognitivas (cerebrais). Na visão do autor caso ocorra à fragmentação do processo de conhecer todo processo de construção "cambaleia" (DEHAENE 2018, p 208).

Dessa forma o handebol é uma modalidade que possui uma grande variedade de descobertas cognitivas para seu praticante. Os passes, fintas, arremessos, recepções e dribles efetuados pelo portador da bola provocam em seu corpo uma singular criatividade pessoal da qual o mesmo se apropria para produzir ações que fazem da modalidade uma sequência de variações de extrema plasticidade corporal, esses elementos chamamos de técnicas, por sua vez essas se apresentam de forma criativa denominada de reserva de ação, ou habilidades (ALMEIDA, DECHECHI, 2012).

A técnica é 0 conjunto de procedimentos que visam um determinado objetivo. Segundo Almeida e Dechechi (2012), a mesma tem como objetivo obter resultados seja na ciência e tecnologia, nas artes ou no esporte. Segundo Vieira e Freitas (2007), no handebol é um elemento que apoia e viabiliza a tática, a execução dos movimentos ou dos fundamentos do jogo.

Nesta pesquisa a ênfase será na técnica de um arremesso (um dos fundamentos do handebol), sendo um gesto complexo e rápido de ataque, que visa à conversão do gol. Este pode ser dividido em seis fases: progressão (corrida), passada, armação do braço, aceleração e desaceleração do braço e acompanhamento (VIEIRA, FREITAS, 2007)

Este trabalho centra-se na técnica de arremesso conhecido como "rosqueta" ou "efeito em rosca", reconhecida como recurso gestual técnico de finta de arremesso, que visa tirar a concentração do goleiro e confundi-lo, retirando da linha da bola e impedindo sua defesa.

Menezes (2012, p. 167) enfatiza que "onde a cooperação entre jogadores da mesma equipe e a relação de oposição caracterizam a imprevisibilidade das ações que ocorrem simultaneamente em diferentes regiões da quadra, influenciando 0 comportamento dos jogadores e os posteriores desencadeamentos técnicos-táticos individuais e coletivos".

A rosqueta pode ser realizada com 01 ou as 02 mãos e leva este nome por causar um efeito de rotação em sentido contrário ao sentido de progressão da bola, o que, ao tocar - solo, causará na bola uma mudança repentina de direção. Para alcançar tal efeito o atleta precisa possuir uma capacidade plástica de movimento simultâneo de braço, ante braço e punho, bem como um controle motor extremo entre os movimentos dos segmentos envolvidos na ação.

Segundo Friedrich Mahlo (1969, p.33) "o produto da percepção em jogo (observação do jogo) é também um processo psíquico que envolve análise das condições". Nesse sentido o que provoca a criatividade gestual e que contribui tecnicamente na solução de problemas avaliados pelo atleta ao perceber a dificuldade de sua leitura de jogo. O que define tanto o objetivo quanto a proposta de uma ação técnica no "arremesso especial da rosqueta", pois para que a finalização tenha seu objetivo alcançado, a leitura qualitativa do posicionamento e velocidade de reação da defesa do goleiro, proporcionará o sucesso ou não na finalização da ação.

Apesar da exigência extrema dos segmentos do corpo, envolvidos na execução da rosqueta, o domínio motor e a plasticidade 
das articulações de punho e dedos, é que proporcionarão um melhor e mais qualitativo efeito na bola.

Por esses parâmetros a necessidade de problematizar sobre essa ação gestual do atleta na modalidade de handebol não com a intenção de mostrar resultado, mais de fazer uma constatação de como seria diferente se as metodologias de ensino fossem aplicadas no sentido de levar o atleta a desenvolver a consciência crítica de sua competência.

\section{MÉTODO}

Buscou-se a investigação bibliográfica de característica narrativa, de autores que sustentam teoricamente o fazer pedagógico do professor. Assim como, a defesa filosófica do esporte como ferramenta de desenvolvimento físico, cognitivo e social. Segundo Santos e Candeloro (2006) a revisão de literatura parte de um projeto de pesquisa, que revela de forma clara e explícita o universo de

\section{DISCUSSÃO}

\section{0 arremesso rosqueta como prática gestual no handebol}

O arremesso especial rosqueta enquanto resultado da criação mental, da socialização corporal de membros, músculos, leituras e cálculos, estímulos visuais, força e dinâmica de ação. Nessa perspectiva este
Nesse diálogo comunicativo entre intenções e ações comandadas pelo cérebro ao corpo, sejam elas planejadas ou não, o presente trabalho procura discorrer suas reflexões sobre a prática gestual do arremesso especial rosqueta e suas particularidades, com o objetivo de refletir no sentido do saber como fazer por parte do aluno/atleta de handebol, destacando a maneira como essa prática gestual vem sendo executada no cotidiano, em uma ação apropriada, ou possivelmente alienada a ele.

contribuições científicas que muitos autores apresentam sobre um determinado tema específico, bem como sua importância para o desenvolvimento de trabalhos acadêmicos. Segundo Rother (2007), as revisões narrativas se baseiam na análise e interpretação dos conceitos apresentados, amparados na percepção subjetiva do autor.

\begin{abstract}
"A aprendizagem de uma tarefa motora (gesto esportivo) aumenta o agrupamento de neurônios e desencadeia uma maior sincronização das unidades motoras no praticante. Dessa forma, a tomada de decisão ocorre em um modelo no qual o processamento de informação pode ser realizado em conjunto, isto é, as operações mentais ocorrem simultaneamente à aprendizagem do gesto esportivo. Dessa forma, o SNC possui a capacidade de modificar algumas das suas propriedades morfológicas e funcionais em resposta às estruturas do ambiente e do tipo de treinamento de habilidades motoras chamada de plasticidade neural" (LEÃO et al., 2017 p 232).
\end{abstract}

Percebe-se que a plástica das ações faz crescer o interesse pela modalidade do handebol, o que torna imprescindível o conhecimento do professor, "no embasamento cientifico", e a certeza da competência desse profissional, no aplicar tais conhecimentos, quando se fizerem necessárias, ações que demonstre crescimento da cognição e a socialização corporal, transformados no desenho da intenção do fazer. Certamente que a habilidade motora se faz presente através de várias junções e elementos que contribuem com esta competência (PERRENOUD, 1999).
A Prática gestual do arremesso especial (rosqueta), no handebol será discutida no corpo deste estudo, a partir dos questionamentos e observações do "saber como fazer" gestual na ação de um atleta em arremessar uma bola, com o objetivo de contornar um obstáculo. Está ação requer um aprendizado e uma consciência corporal que se acredita chamar-se, saber como fazer, competência ou habilidades adquiridas o que significa dizer que, em educação, existem elementos que constituem a base de toda a ação (RAMOS, 2001). 
No handebol há vários tipos de arremessos que levam o jogador a fazer o gol, quando essa intenção é materializada o arremesso se transforma em um objetivo concretizado. A rosqueta é um recurso utilizado pelos extremas ou pontas quando o goleiro se posiciona para fechar o ângulo de arremesso, o jogador coloca uma força de punho na bola que provoca um efeito de giro, a trajetória da bola muda claramente ao contato com qualquer superfície e ignora o goleiro, indo para dentro do gol. É um fenômeno de rotação da bola sobre seu eixo causado pela força nela colocada. Conforme ilustra a figura abaixo.

Figura 01 - Arremesso especial rosqueta, sendo executado a fim de enganar e vencer o goleiro.

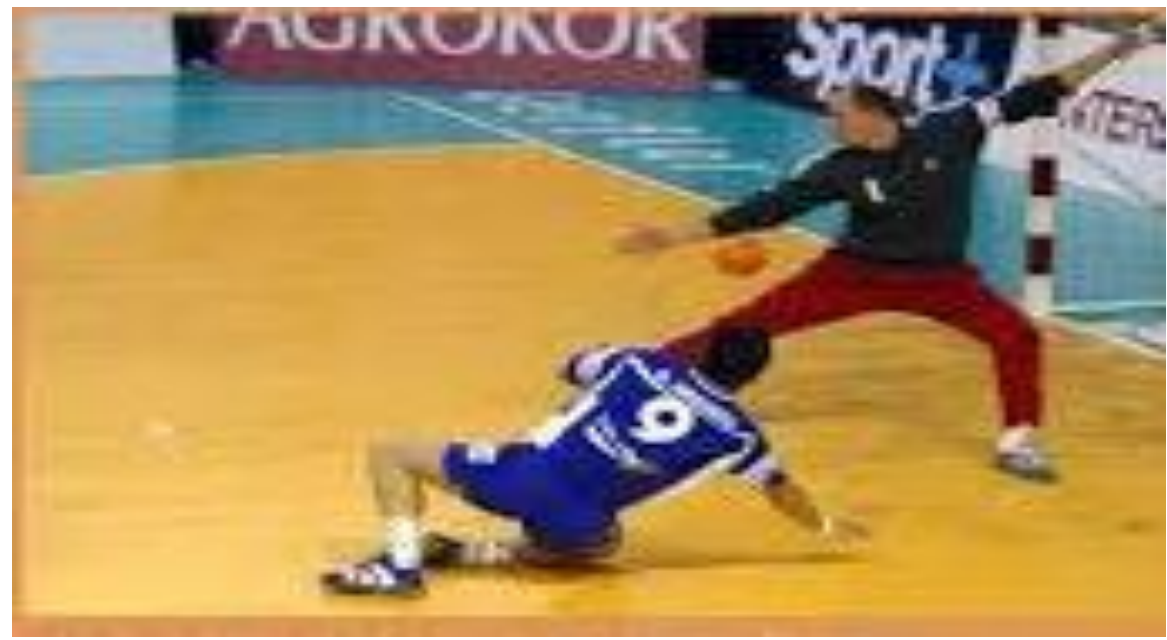

Fonte: http://www.diaadiaeducacao.pr.gov.br/vel2016.

Apesar de não haver material literário que estude o fenômeno gestual de arremesso rosqueta, peculiar do handebol, há registros, de que, foi nos anos 80, que uma atleta Romêna, M. Voinea apresentou pela primeira vez em um arremesso de ala (ponta), esta mecânica de arremesso, da mesma forma o jogador soviético, de origem Bielorusso, Karskasiewitch praticou ação semelhante.

Uma variação desse arremesso seria a rosqueta inversa; mesmo princípio descrito anteriormente, com força aplicada para alcance de outra trajetória ao toque com a superfície.

Rosqueta no ar ou espaço; o efeito é o mesmo da rosqueta em direção ao solo, porém a bola não toca o solo, o jogador completa o gesto com técnica de dedos e mão (quase sempre com a parte inferior da mão), e é usada quando o goleiro se adianta a rosqueta clássica. E outras variações que podem ocorrer nesse tipo de arremesso.

\section{A prática pedagógica da gestualidade esportiva}

$\mathrm{Na}$ educação física as etapas de formação assim como na psicomotricidade a consciência corporal se solidificam com as práticas de movimentos que vem do lúdico ao pedagogicamente elaborado. Ao acompanhar as atividades esportivas identificou-se que a maioria dos atletas inicia e segue por muito tempo executando ações que são elaboradas por reprodução, sem a base cientifica e o conhecimento que solidifique sua eficácia, construção e sentido. Para Bourdieu (2005 p. 116), isso decorre de um sistema obtido por prioridades oriundas de arcabouços cognitivos permanentes produzidos e incorporados de bases materiais objetivas.

Entende-se que toda competência se estabelece por fatores que se associam para fortalecer a prática de cada indivíduo, conforme salienta Perrenoud (1999, p. 30) "O desenvolvimento da competência não se faz, sem a utilização de conteúdo (saberes) que os fundamentem". Essa afirmativa permite concluir que o conhecimento científico, empírico e as experiências de cada professor, formam uma reserva de ação pedagógica, educacional e profissional. O que no tocante a produzir movimentos gestuais estabelecem maior compreensão na comunicação, denominando-se, portanto, de gestos coverbais (CAVALCANTE et al., 2016, apud McNELL, 1992).

A fim de criar de forma consciente uma ação que resulte em um efeito plástico objetivo, e não só alcançar uma vitória em um combate esportivo. Outrossim, baseado em gestos e efeitos primordiais, fazer a diferença no individual de um atleta que" desenha com 
ROSQUETA NO HANDEBOL

seu corpo o gestual" Nascimento (2006), como acentua Berthier adaptado por sua criação "cognitiva" enfatizada por (VYGOTSKY, 1988). É o que o presente trabalho vem analisando e discutindo.

Para Oliver (1995) a corporeidade é uma leitura que o cérebro faz do mundo, sendo o corpo o instrumento relacional. Nesse sentido, em todas as situações o corpo se estabelece no espaço devido a sua compreensão alinhada do cérebro e de suas adaptações como o ambiente, isto é, a forma corpórea do relacionamento corpo - universo.

Por outro lado, os gestos coverbais são produzidos espontaneamente com a fala, afirma Mariane et al., (2015) apud Mcneill (1992); a gesticulação na hora da fala é uma comunicação auxiliar, que acompanha o desenvolvimento da comunicação de forma simultânea. No esporte, segundo o autor, ao se efetuar um gesto técnico com a intenção de vencer obstáculos, se está buscando de forma cognitiva uma comunicação em função da capacidade física, ou seja, obter vantagem sobre a deficiência do oponente, o que não deixa de ser uma configuração comunicativa.

Essa articulação da linguagem gestual corpórea permite aludir a concepção de Descartes (1979, apud ROSA, 2017 p.219), ao conceber o corpo como o cárcere da alma, e a aproximação do pensar a semelhança da razão, traduzindo pelo pensamento o gesto produzido pelo corpo, que executa comandos cognitivos elaborados pelo ato de pensar:

\begin{abstract}
"Assim, por não concebermos que o corpo pense de alguma forma, temos razão de crer que toda espécie de pensamento em nós existente pertence à alma; e [...] devemos crer que todo o calor e todos os movimentos em nós existentes, na medida em que não dependem do pensamento, pertencem apenas ao corpo" (DESCARTES, 1979 apud ROSA, p. 218).
\end{abstract}

Tendo em vista esses processos o referido estudo proporciona alguns direcionamentos ou caminhos que provoquem reflexões sobre a corporeidade constituída entre o cognitivo e o corpo nas ações repentinas do esporte e a criatividade do professor em fornecer elementos que manifestem no aluno no período de sua formação, ferramentas pedagógicas para que o seu "saber como fazer", seja realmente consciente nas suas aplicabilidades (LEÃO et al., 2017, p. 232). "A memória declarativa manifesta-se no "o que fazer", no pensamento tático. Enquanto a memória de procedimento participa no "como fazer", na execução da técnica esportiva".

Em um universo de possibilidade que a corporeidade pode apresentar é possível entender que não se pode separar espírito de corpo (GALLO, 2006) o autor proporciona a possibilidade de ter uma visão clássica de corporeidade:

\begin{abstract}
"A visão de Aristóteles pode ser chamada de orgânica; a alma é aquilo que anima o corpo, mas está plenamente integrada a ele. O movimento, qualquer movimento físico, é feito pelo corpo, mas possibilitado pela ação da alma; da mesma maneira, o pensamento é faculdade da alma, mas só pensamos por que somos corpóreos. Parece-me ficar claro, assim que, para Aristóteles (representando o espírito da cultura grega da época), "corpo ativo" não seria um conceito estranho, posto que o corpo é necessariamente lugar de atividade, garantindo o dinamismo da vida" (GALLO, 2006 p.12,13).
\end{abstract}

Consoante a essa visão percebe-se que a relação corpo - espírito provoca uma comunicação e um efeito nas ações aplicadas de forma coletiva ou corpórea pelo indivíduo, o que fortalece $o$ pensamento de que, o conhecimento do corpo e do espírito pelo próprio individuo the fornece segurança, em fazer ações com objetivos direcionados as suas intenções.

Nesse contexto o ensino aprendizagem, nas mais diversas situações, necessita ser um ponto de grande importância para a prática educacional e esportiva, em especial nos gestos técnicos efetuados pelos 


\title{
ROSQUETA NO HANDEBOL
}

alunos, pois na medida em que a apropriação cognitiva ocorre entende-se, que teoria e prática se constituem uma só unidade (FREIRE, SCAGLIA, 2009).

A corporeidade está presente na evolução dos efeitos gestuais técnicos, permitindo fazer inúmeros estudos sobre muitos movimentos. Por hora este estudo procura ater-se em uma ação gestual denominada arremesso de efeito (rosqueta), que no esporte em especial na modalidade handebol é produzida por uma ação corporal em que o atleta através de uma decisão (cognição), seus membros, e sua força, consegue produzir com auxílio da mão uma pressão sobre a bola que causa um efeito, ofensivo sobre o adversário em uma ação de jogo. O gesto se articula dentro da comunicação de forma natural auxiliando na questão visual de uma troca de conversas (CAVALCANTE et al., 2015, apud McNELL, 1992):

\begin{abstract}
"A gestualidade está relacionada com o planejamento conceitual de uma mensagem a ser verbalizada". Isso implica que: "a) os gestos desempenham um papel importante na constituição do pensamento e da linguagem; b) os gestos têm um papel facilitador nos processos cognitivos" (CAVALCANTE et al., 2015, apud McNEILL,1992, p 57).
\end{abstract}

Para Olivier (1995), a corporeidade reúne ações que interagem dentro das reações causadas por sinapses que formam a comunicação e a criatividade através do desenho mental, associado ao conjunto cognitivo de ideias, membros e gestos na transformação prática e dinâmica da ação do corpo no espaço com o objetivo de realizar um movimento, ou melhor, desenhar com seu corpo (gestos corporais), o movimento cognitivamente elaborado, Conclui-se que o conhecer de algo leva a apropriação do conhecido, códigos, signos, coisas; e também uma autonomia adquirida sobre tal descoberta como afirma a autora. "Conhecer é também deixar de ver" [...] "Quando conheço algo, aproprio-me dele, trago-o para meu universo de referências e deixo de olhar para todas as particularidades que caracterizam aquele algo como único e singular" (OLIVER, 1995. p 3).

$\mathrm{Na}$ defesa desse argumento constatase a contribuição de Elena Pasquinelli (2018 p.
32), "Mesmo na idade adulta o cérebro continua a modificar suas sinapses e o grau de aprendizagem" nessa trajetória, perceber-se que as ações corporais se valem do coletivo complexo dos sentidos, que associados a concentração, memória e aprendizagem podem construir muitas atividades criativas (CLAUDE BASTIEN, 1992, apud MORRIN, 2000. p. 36), nota-se que "a evolução cognitiva não caminha para o estabelecimento de conhecimentos cada vez mais abstratos, mas, ao contrário, para sua contextualização". O que revela a atitude espontânea de cada aluno criar gestos espontâneos na prática esportiva do handebol, a partir de sua própria leitura de jogo.

No paradigma ensino - aprendizagem a troca de conhecimento está presente com muita força e propriedade de ensinar na real situação de aprender. $O$ aprender como bem coloca (DEHAENE, 2018):

"O cérebro humano parece funcionar de um modo diferente através de combinações progressivas de símbolos, o que de acordo com o cérebro basenyano, nós olhamos o mundo com uma vasta combinação de pensamentos potenciais" (DEHAENE, 2018, p 96).

Assim a importância do professor de educação física e de seu conhecimento em psicomotricidade colabora com 0 desenvolvimento do aluno no que se refere ao conhecimento motor e na sua autonomia gestual, criatividade coletiva corporal e principalmente no seu desempenho especializado em modalidades esportivas como o handebol. $O$ educador que consegue oportunizar que seu aluno seja objeto e sujeito da ação em uma linha de entendimento solidifica sua competência em efetuar gestos que previne a presença do conhecimento fragmentado, como explica (MORIN, 2000): 


\section{ROSQUETA NO HANDEBOL}

"A supremacia do conhecimento fragmentado [...] impede frequentemente de operar o vínculo entre as partes e a totalidade, e deve ser substituído por um modo de conhecimento capaz de apreender os objetos em seu contexto, sua complexidade, seu conjunto" (MORIN, 2000, p.14).

Circunscrito por este fundamento constata-se o fazer de alguns movimentos gestuais, por simples acaso e curiosidade criativa, por parte do aluno, sem um prévio conhecimento técnico, pedagógico e educacional adquirido anteriormente nas suas aulas de educação física e treinamentos. 0 número de erros na tentativa de chegar a um acerto leva a diversos caminhos chamados de livre aprendizagem.

Nas práticas esportivas são inúmeras as vezes que o aluno atleta deve se submeter ao treino da rosqueta, até que entenda o processo, a intenção, a necessidade e razão da aplicabilidade do arremesso com efeito e assim seja capaz de decidir qual o melhor momento de executá-la. Quando isso ocorre por parte do aluno, entende-se que, o caminho percorrido para autonomia de aplicar a criatividade será o próximo passo. handebol

\section{A aprendizagem da rosqueta no}

A partir dessas reflexões dos questionamentos apresentados neste trabalho tendo como fundamento no saber científico, na prática desportiva. Verifica-se a dificuldade em vislumbrar a indissociabilidade entre teoria e prática, que permite a fragmentação do conhecimento que para Morin (2000) provoca uma lacuna entre o objetivo e o resultado.

A inteligência parcelada, compartimentada, mecanicista, disjuntiva e reducionista rompe o complexo do mundo em fragmentos disjuntos, fraciona os problemas, separa o que está unido, torna unidimensional o multidimensional. É uma inteligência míope que acaba por ser normalmente cega" (MORIN, 2000. p.43).

O potencial atribuído as funções cerebrais que se materializam nas práticas esportivas por meio da execução gestual, no handebol adquirem características singulares, dentre elas está o arremesso de rosqueta que pode ser mais bem descrita pela trajetória da bola após seu lançamento, que ao atingir qualquer superfície muda sua direção devido a pressão exercida pelos dedos, mãos e outros membros corporais, que se produz por uma construção cognitiva de uma linha em espiral. "A mão humana é um instrumento extremamente versátil, capaz de delicadíssimos movimentos e manipulações, e ao mesmo tempo de fortíssimos apertos" (DORLING, 1994.p 28). Como ilustra a figura abaixo. 


\section{ROSQUETA NO HANDEBOL}

Figura 2 - Atleta em treinamento executando o arremesso Rosqueta.

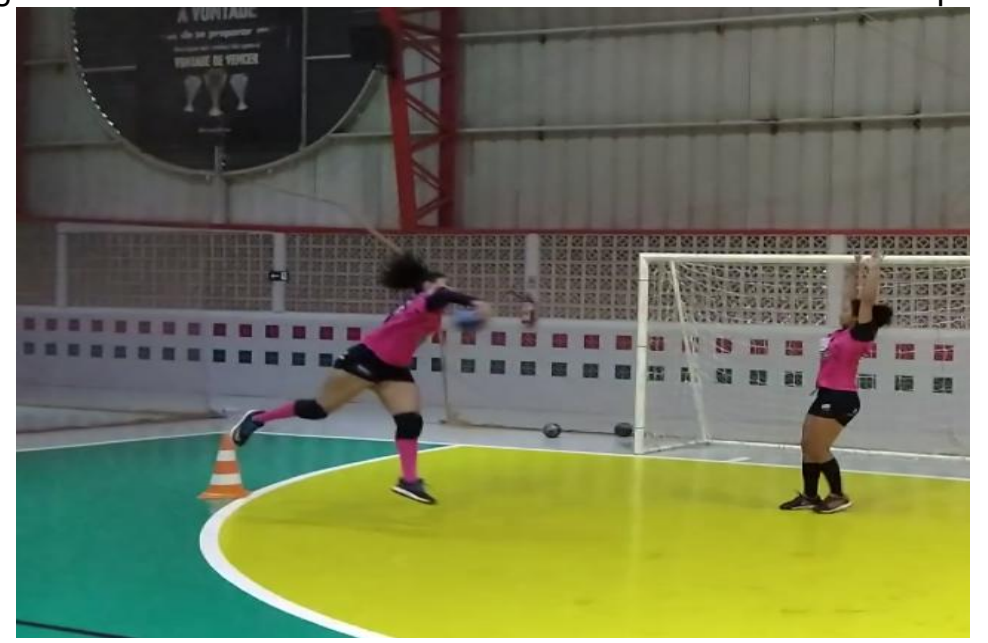

Fonte - Próprios autores.

Para que resultados sejam obtidos é possível misturar potência, resistência e muitas tentativas em ações que permitem uma avaliação da eficiência, e dentro desse processo, a função cognitiva revela-se no desempenho da ação, como fazer? Para que fazer? Quando fazer? Isto tudo deve ser levado em conta na atividade do fazer e do saber-fazer, além disso, no aprender como fazer, o que permite a certeza da autonomia da consciência corporal, Leão e col. (2017) ratificam ao dizer que:

No processo em que se inicia a aprendizagem da tarefa motora, áreas corticais como o córtex pré-frontal, pré-motor, somatossensorial, parietal e occipital são ativadas. À medida que as ações são executadas e repetidas, gradativamente vão tornando-se automatizadas e criam-se redes neurais de novas células ganglionares da base e do cerebelo. Solidificando-se a execução da tarefa, os gânglios da base ficam responsáveis pela periodicidade do movimento, posição corporal e postura, ao passo que o cerebelo estabelece a velocidade necessária para a execução do movimento (LEÃO et tal., 2017, p 232).

Essa máxima levada a cabo na realização do arremesso de efeito rosqueta, expõe a práxis do saber-fazer pelo aluno e do fazer pedagógico do professor/treinador. Uma vez que o uso desse arremesso no comando dado pelo cérebro ao corpo para execução gestual desse arremesso no jogo é um processo intenso, veloz e de leitura do adversário. Mas que quase não acontece por motivos que este estudo passa investigar.

\section{CONCLUSÃO}

Diante dessas proposições escritas é possível fazer uma análise comparativa a partir das observações feitas nos jogos assistidos na Europa entre equipes masculinas e femininas de Handebol, nas diversas
Quais seriam as possíveis causas da não ação por parte do aluno atleta? E ao fazer, é possível reconhecer o grau de criatividade oriunda do próprio aluno?

A baixa frequência do uso dessa habilidade estaria possivelmente imbricada no processo de ensino aprendizagem e na relação professor e aluno? Ou ainda, na falta de apropriação do conhecimento que produz a rosqueta? Essas dúvidas foi uma tentativa descrita nesse estudo.

categorias, em que se constatou a presença acentuada do arremesso rosqueta pelos atletas: respeitando-se as diferenças estruturais desportivas, existentes entre 0 handebol europeu e o brasileiro. Ainda assim 
segue a inquietação do por que dessa prática gestual ser tão pouco executada pelos atletas no Brasil.

É possível afirmar que o medo de errar por parte do aluno/atleta esteja sendo comprometido por seus processos cognitivos, e o medo se envolve com a condução da aula, com o comportamento do professor, o tipo de gestão docente e a liberdade do amadurecimento cognitivo, que se eleva dentro da criatividade do aluno/atleta e da visão observadora do professor, que avalia as possibilidades dos alunos/atletas, e não a severidade do que é imposto a ser feito. Permitindo assim, uma gestão compartilhada em que os indivíduos podem partilhar suas descobertas e ter autonomia nos seus gestos técnicos criativos.

É inegável que o handebol brasileiro tem a sua especificidade única de saber fazer a prática esportiva diferenciada das outras nações, através de suas diversidades de ritmos e de multiplicidade de culturas como africana, indígena, lusitana e muitas outras. Por essas considerações é possível entender que apesar das diferenças existentes nas modalidades esportivas de cada país ou região, a necessidade de abrir novas possibilidades para que os atletas busquem avançar é uma assertiva, é o que faz o conhecimento científico ter seu pleno sentido prático.

As proposições em voga nessas reflexões discorrem exatamente para esse fim: que o professor de educação física busque oportunizar ao aluno/atleta o pleno desenvolvimento do entendimento de suas funções cognitivas por meio do conhecimento, que o torne autônomo em seus gestos corporais de forma confiante e segura. Por entender que o arremesso rosqueta não é um sistema insanável, amarrado em códigos gestuais fechados, mas em primeira instância, a manifestação do uso da liberdade, e que o aluno/atleta precisa entender que tem potencial para se apoderarem dos códigos, oriundos das informações da psicomotricidade, recebendo-os e estabelecendo uma relação salutar entre liberdade e consciência corporal e dessa relação partir para o exercício da corporeidade valendo-se de uma autonomia criativa e empática; foi a priori, o alvo maior deste trabalho.

\section{REFERÊNCIAS}

ALMEIDA, A, G; DECHECHI, C. J. Handebol: conceito e aplicações. 1.ed. Barueri, SP: Manole, 2012.

BASTIEN, C., 1992. In: E. Os Sete Saberes necessário à Educação do Futuro. MORRIN., E. São Paulo: Cortez; Brasília, DF: UNESCO, p.36, 2000.

BOURDIEU, P. Razões práticas: sobre a teoria da ação. 6. ed. Campinas: Papirus, p. 116, 2005.

CADERNOS PDE. ISBN. 978-85-8015-094-0. Disponível em: http://www.diaadiaeducacao.pr.gov.br/portals/cadernospde/pdebusca/producoes pde/2016/201 6 pdp edfis unicentro elvisclebisondossantos.pdf. Acesso em: 29.08.2019.

CAVALCANTE et al. Gestualidade como uma Pista importante da fluência infantil. In: Prolíngua,

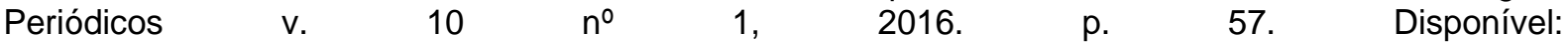
https://periodicos.ufpb.br/index.php/prolinqua/article/view/27586. Acesso em 21 de 04 de 2019.

DEHAENE, S. Apprendre à lire - des sciences cognitives à la salle de classe. Paris: Odile Jacob. p 96, 2018.

DESCARTES, R. 1979. In: A concepção de corpo em René Descartes. ROSA, Daniel A. EMPORIUN. O blog da Faculdade Dom Luciano, 2017. Disponível: http://famariana.edu.br/blog/2017/10/03/aconcepcao-de-corpo-em-rene-descartes/\#_ftnref1. Acesso em 25.06.2019.

DORLING, J. Corpo humano. 4 ed. Editora Ática. p. 28, 1994.

FREIRE, J. B.; SCAGLIA, A. J. Educação como prática corporal. São Paulo: Scipione, 2009. 
GALLO, S. Corpo ativo e a filosofia. In MOREIRA, W. (ORG.). Século XXI a era do corpo ativo. São Paulo: Papirus, 2006.

LEÃO. I. C. S. et al. A importância da neurociência para o esporte coletivo: uma revisão narrativa. Revista de Educação Física / Journal of Physical Education, v. 86, n. 3, p. 230-238, 2017.

MAHLO, F., Acte tactique enjeu. Vigot. Paris. p 30-40, 1969.

MENEZES, R. P.; 2012. O handebol, seu cenário imprevisível e os métodos de ensino aprendizagemtreinamento. In: E-balonmano.com: Revista de Ciências del Deporte. MENEZES, R. P.; REIS; H. H. B; MORATO, M. P. v. 12, n. 3, p. 165-176, 2016.

MORIN, E. Os Sete Saberes necessário à educação do futuro. São Paulo: Cortez; Brasília, DF: UNESCO, p. 36, 2000.

OLIVIER, G. G. F. Um olhar sobre o esquema corporal, a imagem corporal, a consciência corporal e a corporeidade. - Dissertação de mestrado apresentada à Faculdade de Educação Física da Universidade Estadual de Campinas (área de concentração: Educação motora) - p. 3, 1995.

PERRENOUD, P. Construindo as competências. Editora Artmed, 1999.

RAMOS. M. N. A pedagogia das competências autonomia ou adaptação. São Paulo, Cortez, 2001.

ROTHER, E. T. Revisão sistemática x revisão narrativa. Acta Paulista de Enfermagem, São Paulo, v. 20, n. 2, p. 5-6, 2007.

SANTOS, V.; CANDELORO, R. J. Trabalhos acadêmicos: uma orientação para a pesquisa e normas técnicas. Porto Alegre: AGE, p. 73, 2006.

PASQUINELES, H. Capacités du cerveau, Chacun peut progresser. In: SCIENCES ET AVENI SCIENCES ET AVENIR. FR. Juin. n 856 page $32,2018$.

PIAGET, J. Seis estudos de psicologia. Trad. Maria Alice M. D' Amorin e Paulo Sérgio L. Silva. Edição 24. Rio de Janeiro, Forense Universitária,1999.

VIEIRA, S.; FREITAS, A. O que é handebol. Rio de Janeiro, Casa da Palavra, COB, 2007.

VYGOTSKY, L. S. Aprendizagem e desenvolvimento intelectual na idade escolar. In: VYGOTSKY, L. S.; LURIA, A. R.; LEONTIEV, A. N. (Org.). Linguagem, desenvolvimento e aprendizagem. São Paulo: Ícone, p. 57,1988. 